\title{
Pure akinesia: an atypical manifestation of progressive supranuclear palsy
}

\author{
Hidenori Matsuo, Hidetoshi Takashima, Masao Kishikawa, Ikuo Kinoshita, \\ Masataka Mori, Mitsuhiro Tsujihata, Shigenobu Nagataki
}

\begin{abstract}
Two patients with "pure akinesia" who showed the characteristic changes of progressive supranuclear palsy (PSP) at necropsy are described. They had akinesia but no rigidity or tremor, and ophthalmoplegia was not observed during the course of illness. The symptoms of "pure akinesia" was not improved by levodopa therapy but was considerably improved by L-threo-3,4-dihydroxyphenylserine. At necropsy, pathological findings were not different from those reported for PSP. It is suggested that "pure akinesia" is an atypical manifestation of PSP, and that norepinephrinergic neurons may be involved in some types of PSP.
\end{abstract}

"Pure akinesia" is a rare syndrome characterised by the freezing of gait and pulsion symptoms without rigidity or tremor, and by lack of response to levodopa therapy. ${ }^{12}$ Several reports have shown L-threo-3,4-dihydroxyphenylserine(L-DOPS), a synthetic precursor of norepinephrine (NE), to be dramatically effective in treating this condition. ${ }^{34}$ This suggests that the norepinephrinergic neurons of the central nervous system (CNS) may be part of the neurochemical background of the disease. "Pure akinesia" therefore has been seen as a new condition or specific form of Parkinsonism. ${ }^{145}$ As there have been few anatomical studies, the classification of this syndrome is still not clear.

We report the cases of two patients who showed "pure akinesia" and who had good responses to L-DOPS as a clinical manifestation, but who on postmortem examination were found to have had progressive supranuclear palsy (PSP).

\section{Case reports}

\section{Patient 1}

A 72 year old man developed gait disturbance and started to have frequent falls due to difficulty in initiating movement. $\mathrm{He}$ also showed micrographia and festinating speech. A neurological examination showed a lack of facial expression but no associated tremor or rigidity. His eye movements were full, and his tendon reflexes and planter responses were normal, but he had frozen gait which disappeared when he was asked to step forward over the blocks on the floor and to go up or down the staircase (Kinésie paradoxale), and pulsion symptoms. There was no evidence of dementia. A CT scan revealed mild cerebral atrophy and dilatation of the third ventricle. Levodopa was given for several months without benefit. During the next year there was further deterioration in his gait, with episodes of freezing during the initiation of gait and on turning. The freezing phenomenon dramatically improved when he underwent LDOPS therapy $(600 \mathrm{mg} /$ day); the time of initial hesitation in walking decreased considerably and micrographia improved. Two years after the onset of his illness, he died of oesophageal cancer.

\section{Patient 2}

A 62 year old man with no history of neurological disease noticed an increasingly frequent inability to open his eyes. Over the next two years, he developed frozen gait and had frequent falls. His eye symptom and gait disturbance persisted despite treatment with carbidopa-levodopa and with trihexyphenidyl. At a neurological examination two years before his death, he showed a mask-like face and apraxia on opening his eyelids. No restriction of eye movement or ptosis was observed. His speech was low pitched and monotonous, and often festinating. There was no evidence of dementia, rigidity or tremor. His gait was considerably disturbed, freezing occurring on the initiation of movement and on turning. Pulsion symptoms were observed in each direction. An examination of his cerebrospinal fluid and an electroencephalogram showed no abnormality. A CT scan disclosed mild cerebral atrophy. After treatment with L-DOPS (600 $\mathrm{mg} /$ day), the time required to open his eyelid decreased from more than four minutes to less than 30 seconds, and his frozen gait improved slightly. One year later, he showed mild dementia and marked bradykinesia. Magnetic resonance imaging revealed no further abnormality except minimal atrophy of the tegmentum of the midbrain (fig 1). Six months before his death he developed a persistent cough; a chest radiograph disclosed lung cancer. A neurological examination two weeks before his death revealed no abnormality in his oculomotor function, and no axial rigidity or tremor.

\section{Neuropathological findings}

The brains of the two patients weighed 1125 and $1180 \mathrm{gm}$. Gross examinations of both brains showed no external abnormalities, apart from a degree of atrophy that was mainly in the frontal lobe. The sections

Received 24 July 1990.

Accepted 20 September

1990. 
Figure 1 MRI of the brain (Patient 2). No specific lesion is present, the tegmentum of midbrain and slight dilatation of the ventricles. (a) sagittal T1-weighted image, TR $=500, T E=30 ; b$ ) axial proton density image, $T R=2000, T E$ $=20)$.
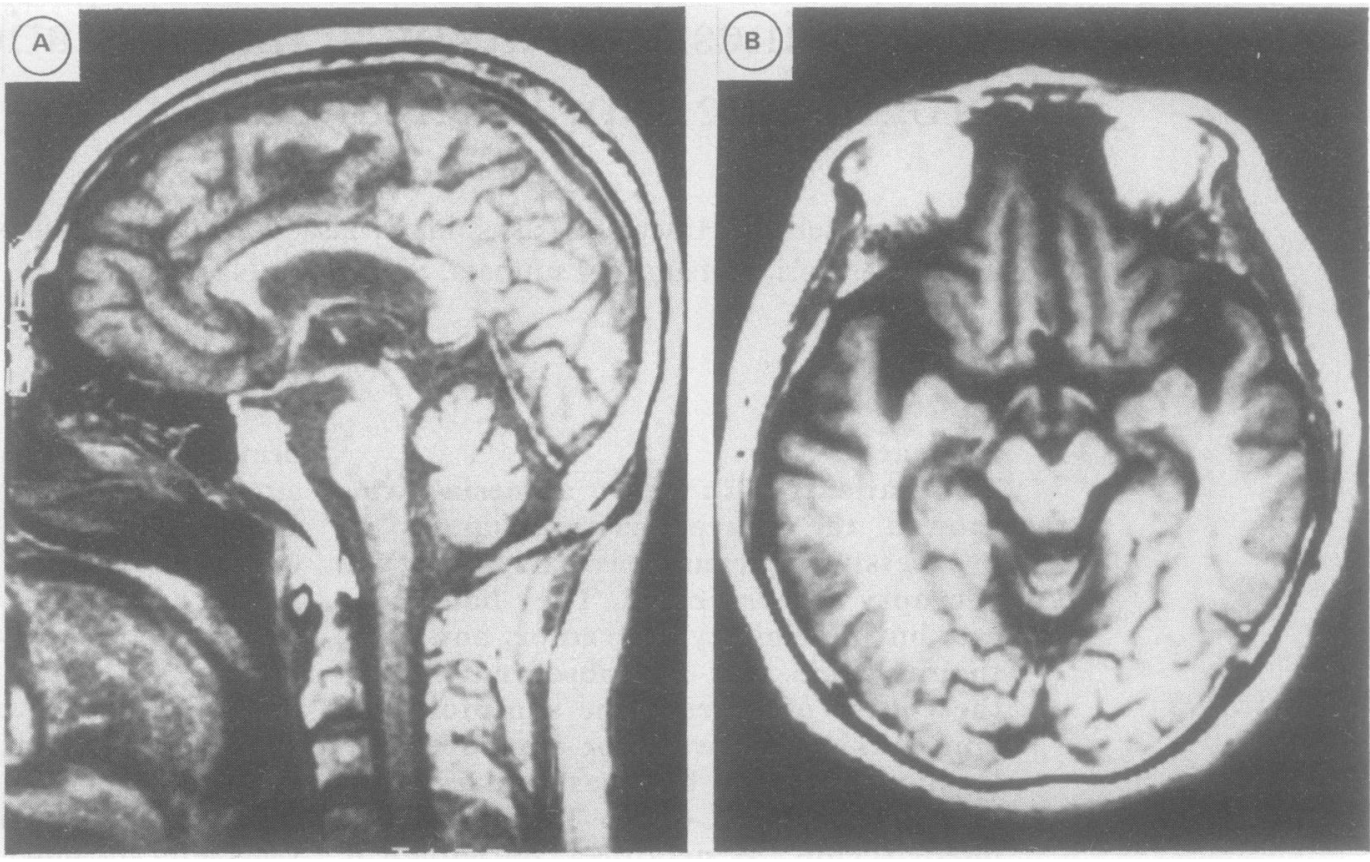

showed that the ventricular system in each brain was slightly to moderately dilated. Both brains showed a slightly brownish colour change of the globus pallidum, the subthalamic nucleus, and marked depigmentation of the substantia nigra. There was mild atrophy in the pontine tegmentum in patient 2 , but no colour change in the locus ceruleus.

Several tissue blocks were taken from the cerebral cortex, basal ganglia, thalamus with subthalamic nucleus, hippocampus, nucleus basalis of Meynert and cerebellum with dentate nucleus of both brains. The brainstem was sampled at several levels. Sections $8 \mu \mathrm{m}$ thick were cut and stained with Hematoxylin and eosin ( $\mathrm{H}$ and $\mathrm{E})$, Nissl, BielschowskyHirano's silver, Bodian, Glial fibrillary acidic protein (GFAP), Holzer, Mallory's phosphotungstic acid hematoxylin (PTAH), Luxol fast blue, S-100 protein, Congo red or periodic acid-Schiff (PAS) stain. To identify senile plaques or neurofibrillary tangles (NFTs), paraffin sections were immunostained with anti- $\beta$ protein or anti-tau. ${ }^{6-8}$
Selected structures were evaluated semiquantitatively (table).

In both cases microscopic examinations revealed the characteristic changes associated with PSP: cell loss, gliosis and neurofibrillary degeneration in a typical distribution (table). The cerebral cortex showed only mild cell loss with few senile plaques and no NFTs. In contrast, severe degeneration associated with cell loss, gliosis and NFTs had taken place in the globus pallidum, subthalamic nucleus, substantia nigra and pontine tegmentum (fig 2). In addition, many neuropil threads were present in the substantia nigra in both brains (fig 3 ). There was no apparent cell loss in the locus ceruleus, but many intracelular NFTs showed up on anti-tau immunostaining. Vacuolar degeneration was seen in the oculomotor nucleus and abducent nucleus in patient 2. There were no Lewy bodies in either brain.

\section{Discussion}

The freezing phenomenon as the predominant

Table Neuropathological findings

\begin{tabular}{|c|c|c|c|c|c|c|}
\hline \multirow[b]{2}{*}{ Brain weight (gm) } & \multicolumn{3}{|l|}{ Patient 1} & \multicolumn{3}{|l|}{ Patient 2} \\
\hline & $\begin{array}{l}1,125 \\
\text { Cell loss }\end{array}$ & Gliosis & NFTs & $\begin{array}{l}1,180 \\
\text { Cell loss }\end{array}$ & Gliosis & NFTs \\
\hline Cerebral cortex & \pm & - & - & \pm & - & - \\
\hline $\begin{array}{l}\text { Putamen } \\
\text { Pum }\end{array}$ & $\bar{t}$ & + & + & $\bar{t}$ & + & + \\
\hline Globus pallidum & ++ & ++ & ++ & ++ & ++ & +++ \\
\hline Nucleus basalis of Meynert & + & ++ & + & + & $+t$ & $+t$ \\
\hline Thalamus & + & + & + & + & + & + \\
\hline Paraventricular nucleus & \pm & + & \pm & \pm & + & + \\
\hline Subthalamic nucleus & + & ++ & $\bar{t}$ & $\bar{t}+$ & $+t$ & + \\
\hline Hippocampus & - & - & + & - & - & + \\
\hline Substantia nigra & $++t$ & +++ & $++t$ & $+t+$ & +++ & $+t+$ \\
\hline Oculomotor nucleus & + & + & + & + & & ++ \\
\hline Interstitial nucleus of Cajal & ND & ND & ND & \pm & + & \\
\hline Periaqueductal matter & + & + & $+t$ & $\bar{t}$ & $+t$ & $+t$ \\
\hline Pontine tegmentum & + & $+t$ & $+t$ & + & ++ & +++ \\
\hline Locus celureus & \pm & + & $+t$ & - & + & $+t$ \\
\hline Pontine nucleus & $\bar{z}+3+$ & \pm & + & - & \pm & + \\
\hline Dentate nucleus & + & $\bar{t}+$ & + & + & $\bar{t}+$ & + \\
\hline
\end{tabular}

NFTs $=$ neurofibrillary tangles; $-=$ negative or none; $t=$ fair or rare; $t=$ mild or occasional; $++=$ moderate or considerable; $+++=$ severe or frequent $\mathbf{N D}=$ not done. 


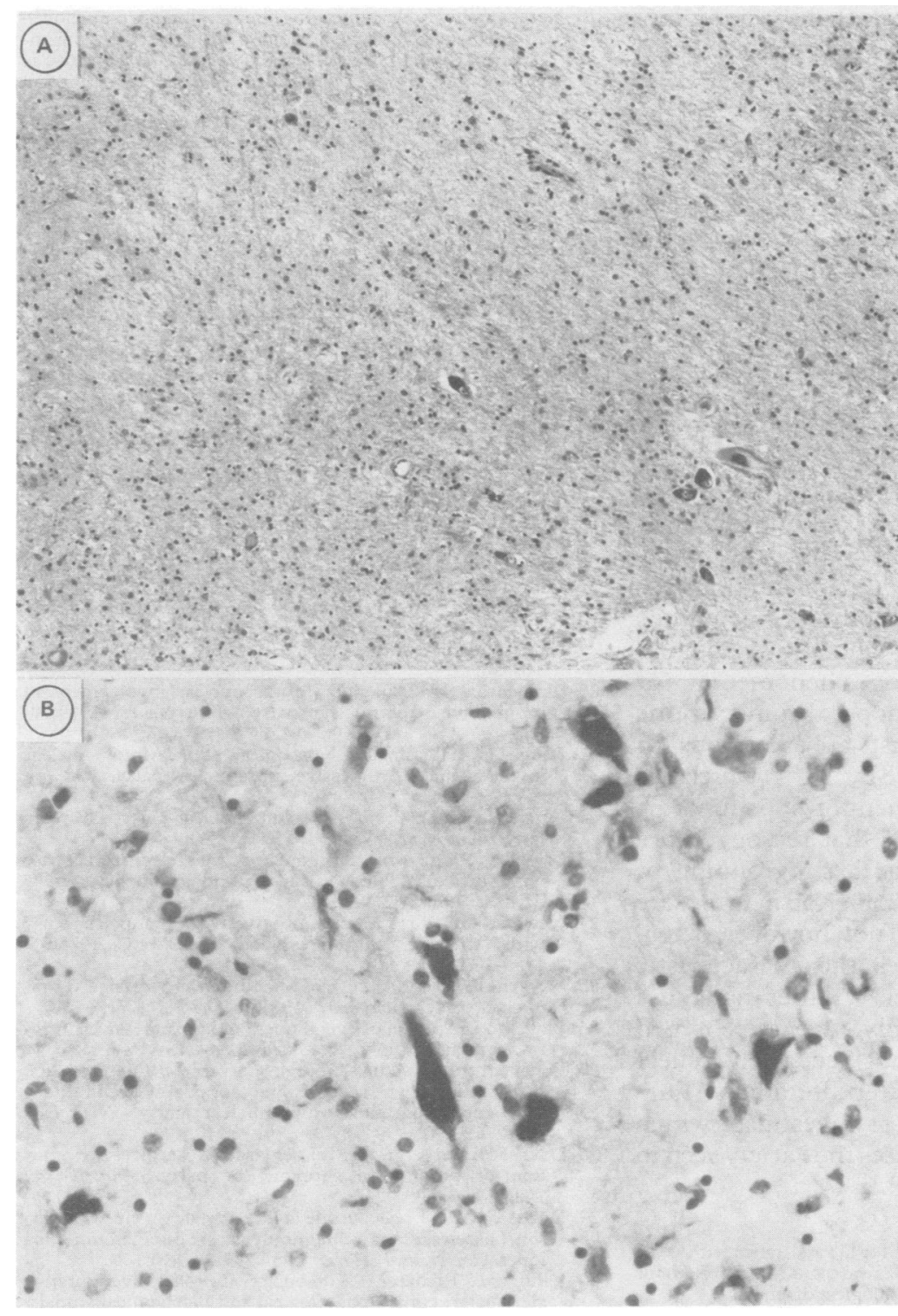

Figure 2 a) Patient 2. Marked cell loss and gliosis in the substantia nigra (HE $E$ $\times 95)$. b) Patient 1. Neurofibrillary tangles in the pontine tegmentum (Anti-tau stain, demelanisation, $\times 380$ ).

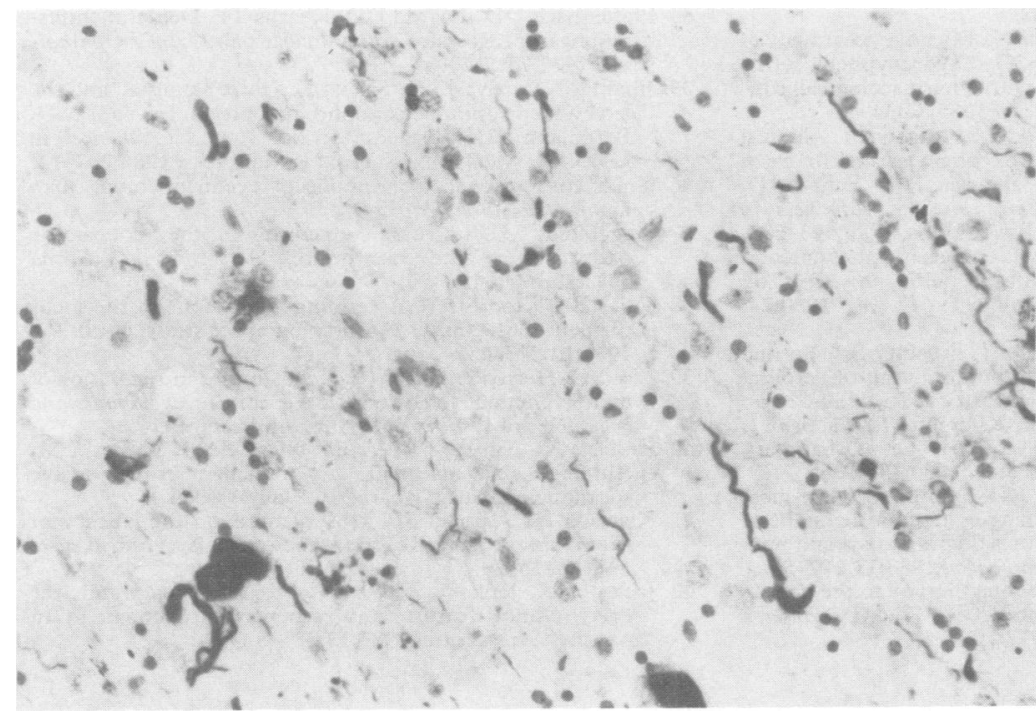

Figure 3 A large number of neuropil threads and neurofibrillary tangles in the substantia nigra. Patient 2. (Anti-tau, demelanisation, $\times 380$ ). feature of akinesia is usually associated with the following conditions: 1) an almost pure akinetic syndrome without rigidity or tremor (as reported by Barbeau'), for which levodopa is effective and which suggests a deficiency of dopamine in the striatum; 2) pure akinesia characterised by the freezing phenomenon with no rigidity or tremor (as reported by Narabayashi et al $^{1}$ ), in which the lack of response to levodopa treatment suggests that it is unlikely that a deficiency in dopamine is the cause; 3) long-standing Parkinsonism treated chronically with levodopa; ${ }^{10-12}$ and 4) the freezing phenomenon related to bradykinesia, itself. In our cases, no symptoms indicative of Parkinsonism other than akinesia were observed, nor did the freezing phenomenon improve when levodopa therapy was given. This corresponds to the "pure akinesia" reported by Narabayashi et al.

Only one or two pathological studies of this condition have been reported. Honma et al reported the necropsy examination of a patient with PSP who manifested initially "pure akinesia", but later also showed supranuclear ophthalmoplegia. ${ }^{13}$ They also reported that two other patients with "pure akinesia" developed dementia, supranuclear ophthalmoplegia, pseudobulbar palsy and nuchal rigidity during their illnesses which lasted for more than 10 years, and emphasised that PSP may be an underlying disease of pure akinesia. ${ }^{14}$ Quinn et al recently reported a case of pure akinesia produced by Lewy body Parkinson's disease, ${ }^{15}$ which responded to levodopa but not to L-DOPS, which indicated that it differed from the "pure akinesia" described by Narabayashi et al. ${ }^{1}$ The pathological findings of our cases resemble those of Honma et al and are consistent with previous reports of PSP, ${ }^{96-22}$ even though no clinical signs indicative of PSP were found.

PSP has been described as a distinct clinicopathological entity, ${ }^{16}$ but several unusual symptoms have been reported that include torticollis, blepharospasm, dysfluency, apraxia of eyelid opening and the freezing phenomenon. ${ }^{23-28}$ Several pathology reports have also described PSP with no eye movement disorder during the patient's life $\mathrm{e}^{28-32}$ and cases in which there was a delay in ophthalmoplegia of up to 12 years. ${ }^{32-34}$ Furthermore, features similar to those of "pure akinesia" have been present in cases described by Steel et al, ${ }^{16}$ and by Davis et al. ${ }^{28}$ In a small number of patients with PSP, "pure akinesia" may be the only symptom in the early stage of the illness. Most of the reported cases of "pure akinesia" are atypical presentations of PSP. In fact, neurootological examinations of three patients with "pure akinesia" have disclosed supranuclear ophthalmoplegia that suggests cerebellar and midbrain tegmental involvement. ${ }^{35}$

L-DOPS treatment had a beneficial effect on each of our patients. The frozen gait and micrographia of patient 1 improved, and the apraxia of eyelid opening (which seems to be a freezing phenomenon because of the difficulty in initiating the act of opening the eyelid ${ }^{36}$ ) and the frozen gait of patient 2 improved. The 
efficacy of L-DOPS suggests that the norepinephrinergic neurons are involved in this condition. Norepinephrinergic neurons are distributed widely throughout the CNS: in the cerebral cortex, hypothalamus, limbic system, globus pallidum, cerebellum, spinal cord and the locus ceruleus. ${ }^{3738}$ Some are assumed to affect movement by regulating the drive components of motility, posture and locomotion. ${ }^{39}$ Because the highest NE concentration is in the CNS, the lesion of the locus ceruleus may be responsible for "pure akinesia, ${ }^{38}$ whereas we found only mild involvement with NFTs. Recently Koller et al transplanted autologus adrenal medullary cells to the caudate nuclei of three patients with PSP. ${ }^{40}$ It is worth noting that one patient showed marked improvement of his postural instability, but the pharmacological basis of this transplantation was not documented. Norepinephrinergic neurons may be involved in PSP and cause postural instability or the freezing phenomenon (or "pure akinesia"). Levodopa, bromocriptine and other dopamine agonists are efficacious for some symptoms of PSP, 22 41-42 which is indicative of the involvement of dopaminergic neurons or receptors. For that reason, "pure akinesia" may actually be a subgrouping of PSP, in which norepinephrinergic neurons are deeply involved. We could not, however, determine which lesion causes the characteristic symptoms of "pure akinesia", rather than those of typical PSP. Probably the stereotyped pathological lesions do not accurately reflect underlying neurotransmitter alterations. Further studies are planned to investigate which transmitter deficiency causes the variety seen in the clinical picture of PSP.

We thank Dr Hiromasa Kuratsune for his assistance with these investigations, and Drs Yoshihisa Kawase and Masahiro Ito for their helpful comments on the pathological diagnosis.

1 Narabayashi H, Imai H, Yokochi $M$, et al. Cases of pure akinesia without rigidity and tremor and with no effect by L-Dopa therapy. In: Birkmayer W, Horniekiewicz O, eds. Advances in parkinsonism. Basel: Roche, 1976:335-42.

2 Narabayashi $H$. Clinical analysis of akinesia. J Neural Transm 1980;suppl 16:334-42.

3 Yamamoto $M$, Ujike $H$, Ogawa N. Effective treatment of pure akinesia with $\mathrm{L}$-threo-3,4-dihydroxyphenylserine (DOPS): Report of a case, with pharmacological con(DOPS): Report of a case, with pharmacological
siderations. Clin Neuropharmacol 1985;8:334-42.

4 Narabayashi H, Kondo T, Yokochi F, Nagatsu T. Clinical effects of $L$-threo-3,4-dihydroxyphenylserine in cases
of parkinsonism and pure akinesia. In: Yahr $\mathrm{MD}$, of parkinsonism and pure akinesia. In: Yahr MD, Bergmann KJ, eds. Parkinson's disease (Advances in

$5 \mathrm{Imai} H$. Syndrome of pure akinesia or freezing phenomenon without rigidity and tremor and with no effect by L-DOPA therapy. Adv Neurol Sci (Tokyo) 1980;24: 838-48.

6 Kitamoto T, Ogomori K, Tateishi J, Prusiner SB. Formic acid pretreatment enhances immunostaining of cerebral and systemic amyloidosis. Lab Invest 1987;57:230-7.

7 Ryong-Woon Shin, Ogomori K, Kitamoto T, Tateishi J. Increased tau accumulation in senile plaques as a hallmark in Alzheimer's disease. Am J Pathol 1989;134:1365-71.

8 Yen S-H, Horopian DS, Terry RD. Immunocytochemica comparison of neurofibrillary tangles in senile dementia of Alzheimer type, progressive supranuclear palsy, and postencephalic parkinsonism. Ann Neurol 1983;13:172-5.

9 Barbeau A. Contribution of levodopa therapy to the neuropharmacology of akinesia. In: Siegfried J, ed. Parkinson's disease. Bern: Hans Huber, 1972:157-74.
10 Narabayashi $H$, Nakamura $R$. The freezing phenomenonproblems in long-term L-dopa treatment for parkinsonism. In: Rose FC, Capildeo R, eds. Research progress in Parkinson's disease. Tunbridge Wells, Kent: Pitman Medical, 1981:1057-63.

11 Ambani LM, Van Woert HM. Start hesitation-a side effect of long-term levodopa therapy. $N$ Engl $J$ Med 1973;288:1113-5.

12 Barbeau A. Six years of high-level levodopa therapy in severely akinetic parkinsonian patients. Arch Neurol 1976;33:333-8.

13 Honma Y, Takahashi H, Takeda S, Ikuta F. An autopsy case of progressive supranuclear palsy showing "pure akinesia without rigidity and tremor and with no effect by L-DOPA therapy (Imai)". Brain Nerve (Tokyo) 1987;39:183-7.

14 Yuasa $T$, Honma $Y$, Takahashi $H$, et al. Progressive supranuclear palsy with pure akinesia as an initial symptom. Neurological Medicine (Tokyo) 1987;26:460-7.

15 Quinn NP, Luthert P, Honavar M, Marsden CD. Pure akinesia due to Lewy body Parkinson's disease: a case with pathology. Mov Disord 1989;4:85-9.

16 Steele JC, Richardson JC, Olszewski J. Progressive supranuclear palsy. Arch Neurol 1964;10:333-59.

17 Steel JC. Progressive supranuclear palsy. Brain 1972; 95:693-704.

18 Tagliavini F, Pilleri G, Gemigrani F, Lechi A. Neuronal loss in the basal nucleus of Meynert in progressive supranuin the basal nucleus of Meynert in progressive supran

19 David NJ, Mackey EA, Smith JL. Further observations in progressive supranuclear palsy. Neurology 1968;18: progressive
$349-56$

20 Blumenthal H, Miller C. Motor nuclear involvement in progressive supranuclear palsy. Arch Neurol 1969;20: 362-7.

21 Ishino $H$, Higashi $H$, Kuroda $S$, et al. Motor nuclear involvement in progressive supranuclear palsy. $J$ Neurol Sci 1974;22:235-44.

22 Kristensen MO. Progressive supranuclear palsy-20 years later. Acta Neurol Scand 1985;71:177-89.

23 Janati A. Progressive supranuclear palsy: report of a case with torticollis, blepharospasm, and dysfluency. Am J Med Sci 1986;292:391-2.

24 Newman GC. Treatment of progressive supranuclear palsy with tricyclic antidepressants. Neurology 1985;35: with tricyc

25 Dehaene I. Apraxia of eyelid opening in progressive supranuclear palsy. Ann Neurol 1984;15:115.

26 Jankovic J. Apraxia of eyelid opening in progressive supranuclear palsy. Reply. Ann Neurol 1984;15:115-6.

27 Bonaventura I, Matias-Guiu J, Cervera C, Puiggros AC. Neuroacanthocytosis syndrome, apraxia of eyelid opening, and progressive supranuclear palsy. Neurology 1986;36:1276.

28 Davis PH, Bergeron C, McLachlan DR. Atypical presentation of progressive supranuclear palsy. Ann Neurol 1985;17:337-43.

29 Dubas F, Gray F, Escourolle R. Maladie de Steele-Richardson-Olszewski sans ophtalmoplégia: six cas anatomo-cliniques. Rev Neurol (Paris) 1983;139:407-16.

30 Jellinger $K$, Riederer $P$, Tomonaga M. Progressive supranuclear palsy: clinico-pathological and biochemical studies. clear palsy: clinico-pathological and bioch
J Neural Transm 1980;suppl 16:111-28.

31 Probst A. Dégénérescence neurofibrillaire sous-corticale sénile avec présence de tubules contournés et de filaments droist: form atypique de la paralysie supranucléaire progressive. Rev Neurol (Paris) 1977;133:417-28.

32 Perkin GD, Lees AJ, Stern GM, Kocek RS. Problems in the diagnosis of progressive supranuclear palsy. Can J Neurol Sci 1978;5:167-73.

33 Nuwer R. Progressive supranuclear palsy despite normal eye movements. Arch Neurol 1981;38:784.

34 Pfaffenbach DD, Layton DD, Kearns TP. Ocular manifestations in progressive supranuclear palsy. Am J Ophthalmol 1972;74:1179-84.

35 Imai H, Narabayashi H, Sakata E. "Pure akinesia" and the later added supranuclear ophthalmoplegia. In: Yahr MD, Bergmann KJ, eds. Parkinson's disease (Advances in neurology, vol. 45). New York: Raven Press, 1986:207-12.

36 Gourology, vol. 45). New York: Raven Press, 1986:207-12. Ophthalmol 1965;73:155-9.

37 Ungerstedt $U$. Stereotaxic mapping of the monoamine pathways in the rat brain. Acta Physiol Scand 1971 ;suppl:1-48.

38 Jones BE, Moore RY. Ascending projections of the locus ceruleus in the rat. II. Autoradiographic study. Brain Res 1977;127:23-53.

39 Lloid G, Hornykiewicz $O$. Catecholamines in regulating of motor function. In: Friedhoff AJ, ed. Catecholamines and behavior, vol 1. New York: Plenum Press, 1975:41.

40 Koller WC, Morantz R, Vetere-Overfield B, Waxman M Autologous adrenal medullary transplant in progressive supranuclear palsy. Neurology 1989;39:1066-8.

41 Klawans HL, Ringel SP. Observations on the efficacy of l-dopa in progressive supranuclear palsy. Eur Neurol 1971;5:115-29.

42 Jackson JA, Jankovic J, Ford J. Progressive supranuclear palsy: clinical features and response to treatment in 16 patients. Ann Neurol 1983;13:273-8. 